\title{
Can Advanced Maternal Age Negatively Impact the Prognosis of Birth? An Observational Study at the Issaka Gazoby Maternity Center in Niamey, Niger
}

\author{
Kamaye Moumouni \\ Alido Soumana \\ Département de Médecine et Specialités FSS, \\ Université Abdou Moumouni de Niamey, Niger \\ Haoua Yahaya \\ Moumouni Garba \\ Service de Pédiatrie Hôpital National de Niamey, Niger \\ Oumarou Zaratou \\ Service de Néonatalogie Maternité Issaka Gazobi, Niamey, Niger \\ Jina Lailatou \\ Service de Pédiatrie Hôpital National de Niamey, Niger \\ Amadou Aicha \\ Service de Néonatalogie Maternité Issaka Gazobi, Niamey, Niger
}

Doi: 10.19044/esj.2018.v14n9p93 URL:http://dx.doi.org/10.19044/esj.2018.v14n9p93

\begin{abstract}
Background: Childbirth at an advanced age is increasing rapidly in the world. This is due to sociological changes and to the development of medically assisted procreation. There are still gaps in knowledge about the risks associated with pregnancy among older women. The objective of our study is to investigate the perinatal risk factors of pregnancy of women over the age of 35, who gave birth at Issaka Gazoby Maternity center in Niamey. Methods: It was a prospective case-control study that spread over 4 months (from January 1 to April 30, 2014). For each parturient whose age is greater than 35 years, we assigned them to two witnesses whose age is between 20 and 34 years. Data obtained from 100 women aged over 35 years and 200 women aged 20-34 years and their newborns were analyzed. Through univariate and multivariate analyses, we sought an association between maternal characteristics and perinatal prognosis. Results: The mean age of the case patients was 38.79 years. The mean age of the controls was 26.93 years. The mean parity of the cases was 6.83 children and that of the controls was 2.33 children. In the case patients, $50 \%$ of pregnancies were completed without complications compared to $51.5 \%$ of controls. The main
\end{abstract}


complications were anemia, threat of preterm delivery, and pre-eclampsia. Seventy-three percent of older women underwent caesarean section. Obstructed labor, retro-placental hematoma, stationary dilation cervix, and pre-eclampsia were the main reasons for the caesarean section. The proportion of low birth weight was $27 \%$ among the case patients and $28 \%$ among the controls. Nine percent of the newborns in the cases had macrosomia as opposed to $4 \%$ in the control group. There was no significant relationship between maternal age and prematurity $(\mathrm{OR}=0.24,95 \% \mathrm{CI}: 0.02$ and $1.96, \mathrm{P}$ $=0.13)$. Statistical analysis found no significant relationship between maternal age and low birth weight $(\mathrm{OR}=2.37,95 \% \mathrm{CI}$ : 0.88 and $6.35, \mathrm{P}=0.07)$. The risk of having a low Apgar score was higher in the case patients $(\mathrm{OR}=0.53$, 95\% CI: 0.32 and $0.88, \mathrm{P}=0.02$ ). Older women were 2.87 times more likely to have a stillbirth child than controls $(\mathrm{OR}=2.87,95 \% \mathrm{CI}: 1.41$ and $5.83, \mathrm{P}=$ $0.002)$. Conclusion: Neonatal mortality is higher in women over 35 years of age.

Keywords: Advanced maternal age, perinatal prognosis, Niger

\section{Introduction}

The average age at childbirth has changed considerably over the last four decades, particularly in the industrialized countries where it has been rising. It has increased from 23.7 years in 1969 to 29.4 years in 2009 in the United States (Statistics Canada, 2012). In Canada, the proportion of women giving birth after 35 years has doubled. It rose from $9.2 \%$ in 1991 to $18.3 \%$ in 2009 (Statistics Canada, 2012). This is due to recent sociological and economic changes and the development of medically assisted procreation in the last fourty years. In our context, low adherence to family planning, particularly in traditional environments, combined with the desire to have a larger family, means that women are constantly procreating from puberty to menopause. Several studies have shown an association of advanced maternal age with complications such as in utero fetal death, prematurity, low birth weight or macrosomia, pre-eclampsia, and gestational diabetes (Joseph et al., 2005; Berkowitz et al., 1990). Other studies reported that advanced maternal age does not affect neonatal prognosis (Cleary-Goldman et al., 2005). In Niger, to our knowledge, no studies have been reported in the medical literature on perinatal prognosis of pregnancies in women aged over 35 years. Our aim was to investigate the obstetric and neonatal risk of pregnancy in a population of women aged over 35 years compared to a population of women aged 20 to 34 years. 


\section{Patients and Methods \\ Study Design and Site}

This was a case-control study that was carried out over a period of 4 months (January 1 to April 30, 2014) at Issaka Gazobi Maternity (IGM) center in Niamey which is an obstetric and neonatal tertiary referral center, covering the region of Niamey and the surrounding areas. It contains 142 hospital beds of obstetric and 31 infant care beds. It records 7,500 deliveries and 3,800 neonatal admissions on the average per year.

\section{Study Population}

The cases were parturients aged 35 years or over and their newborns aged 0 to 7 days. We assigned them to two witnesses (one case for two witnesses). However, these parturients were aged 20 and 34 who had given birth on the same day and under the same conditions as the case and their newborns. Mothers were the secondary target of the study. We excluded newborns referred from another center, abortions, and those who refused to participate in the study.

\section{Ethical Consideration}

The study was approved by the Institutional Review Board of the University of Niamey and the Committee of Ethics, Issaka Gazoby Maternity. Participation was voluntary and written informed consent was obtained from participants.

\section{Operational Definitions of Variables}

For the purposes of this study, we defined primipara as a woman who has given birth for the first time. Pauciparous is the one who has given birth 2 to 3 times. Multipara is the one who has experienced 4 to 6 deliveries. Grand multipara is the woman who has had 7 or more deliveries. According to the World Health Organization (WHO), a woman of advanced maternal age is the one whose age is over or equal to 35 years. Perinatal risk is the probability of morbidity and mortality for the pregnant woman and the foetus starting from the 22nd week of amenorrhea, then the mother and the newborn after delivery. The housewife is defined as any woman whose main activity is housework.

\section{Parameters Studied}

For each mother, we collected socio-demographic data (age, occupation, and residence), obstetrical and medical history, pregnancy monitoring, pregnancy complications, and mode of delivery. For each newborn, we collected gestational age at birth, sex, birth weight, Apgar score at birth, necessity of resuscitation or not at birth, the existence of congenital 
malformations, neonatal complications, and the mode of discharge from maternity center.

\section{Statistical Analysis}

The data were entered into the Epi Info software version 3.5.2 and then exported and analyzed using the STATA 12 software. We used Yates' Chi square test for qualitative variables and Fisher's exact test when the conditions to use Chi square test are not met; this entails the odds ratio (OR) and confidence interval for perinatal risk assessment. $\mathrm{P}<0.05$ was considered to be statistically significant.

\section{Results}

Our sample consisted of 100 cases and 200 controls. The mean age of cases was 38.79 years with extremes of 35 to 47 years. The mean age of the controls was 26.93 years. The mean parity of the case patients was 6.83 children and that of the controls was 2.33 children. The maximum parity was 14 children for the cases and 10 for the controls. Most of the cases and the controls had a low level of education. Table 1 summarizes the sociodemographic characteristics of the patients. Housewives accounted for $72 \%$ of cases and $61.5 \%$ of controls. Sixty-one percent of the case patients and $76 \%$ of the controls lived in urban areas. The mean number of antenatal visits was $3.08 \pm 1.53$ and $3.29 \pm 1.58$ for cases and controls respectively. Three percent of the case patients and $6.5 \%$ of the controls did not receive any prenatal care. Of the cases, $40 \%$ had received more than 4 prenatal consultations while $47 \%$ of the controls had more than 4 . From case patients, $50 \%$ of pregnancies were completed without complications compared to $51.5 \%$ of controls. The main complications during pregnancy (Table 2) were: anaemia, 9\% for the cases and $16 \%$ for the controls; the threat of preterm delivery, $6 \%$ for cases and $10.5 \%$ for controls; and preeclampsia with $3 \%$ for cases and $5.5 \%$ for controls. Twenty-six percent of the cases had a vaginal delivery and $73 \%$ had a caesarean section. In the controls, $24.5 \%$ were delivered by vaginal delivery versus $75.5 \%$ by caesarean sections. The main indications for caesarean sections were: Obstructed labor (6\% versus $26 \%$ ); Retro-placental hematoma (10\% versus 11\% control); Stationary dilation (4\% versus 9\% control); Premature rupture of membranes (25\% versus $15 \%$ controls); and Preeclampsia / eclampsia ( $7 \%$ versus $8 \%$ control). The mean gestational age was 38.08 weeks and 37.25 weeks respectively for the cases and controls. For the cases, $83 \%$ of births were at term compared with $17 \%$ of premature births. For the controls, $84 \%$ of births were at term; $4 \%$ were post term; and $12 \%$ premature. The mean birth weight was $2950 \pm 735 \mathrm{~g}$ and $2885 \pm 733 \mathrm{~g}$, respectively, for the cases and controls. Table 3 summarizes the characteristics of the newborns. The proportion of low birth weight was $27 \%$ in the cases and 
$28 \%$ in the controls. Nine percent of the cases (newborn) were macrosomic as opposed to $4 \%$ of the controls. The rest of the newborns weighed between $2500 \mathrm{~g}$ and $4000 \mathrm{~g}$. Table 4 summarizes the neonatal prognosis. For $35 \%$ of the cases (newborns), the Apgar score was less than 7 at 5 minutes compared to $26.5 \%$ of the controls. We found 6 cases of congenital malformations in the cases ( 3 cases of trisomy 21, 2 cases of spina bifida, and 1 case of ichthyosis) compared to 4 cases of congenital malformations in the controls (one case of spina bifida, two cases of trisomy 21 , and one case of anorectal malformation). We had 20 deaths in cases (newborns) including 14 stillborn and 6 cases of neonatal deaths. Among the witnesses, there were 16 deaths, including 5 stillborn and 11 cases of neonatal death.

Table 1. Socio-demographic characteristics

\begin{tabular}{c|ccc|} 
& Cases N(\%) & Control N(\%) & $P$ \\
\hline \multirow{2}{*}{ Illiterate } & \multicolumn{2}{|c|}{ Level of education } \\
Primary & $39(39 \%)$ & $82(41 \%)$ & 0.09 \\
Secondary & $27(27 \%)$ & $27(13.5 \%)$ & 0.03 \\
Superior & $23(23 \%)$ & $54(27 \%)$ & 0.65 \\
& $11(11 \%)$ & $37(18.5 \%)$ & 0.20 \\
Student & Professional activities & 0.850 \\
Official & 0 & $21(10.5 \%)$ & 1.17 \\
Tradeswoman & $6(6 \%)$ & $41(20.5 \%)$ & 0.59 \\
Housewife & $72(72 \%)$ & $17(7.5 \%)$ & 0.002 \\
& & $123(61.5 \%)$ & 0.03 \\
Urban & $61(61 \%)$ & Residence & 0.750
\end{tabular}

Table 2. Pathologies during pregnancy

\begin{tabular}{c|ccccc} 
Pathology & $\begin{array}{c}\text { Cases } n \\
(\%)\end{array}$ & Controln(\%) & OR & CI (95\%) & $P$ \\
\hline Hepatitis B & $1(1 \%)$ & $3(1.5 \%)$ & 1 & $0.1 ; 9.72$ & 0 \\
HIV & $2(2 \%)$ & $5(2.5 \%)$ & 1.2 & $0.23 ; 6.28$ & 0.09 \\
Diabetes & 0 & $1(0.5 \%)$ & 0 & 0 & 1
\end{tabular}




\begin{tabular}{|c|c|c|c|c|c|}
\hline Syphilis & $1(1 \%)$ & $1(0.5 \%)$ & 3.02 & $0.19 ; 48.74$ & 0.5 \\
\hline Hypertension & $5(5 \%)$ & 0 & 0 & 0 & 1 \\
\hline Heart disease & $1(1 \%)$ & 0 & 0 & 0 & 1 \\
\hline Malaria & $19(19 \%)$ & $22(11 \%)$ & 1.9 & $0.97 ; 3.7$ & 0.31 \\
\hline $\begin{array}{l}\text { Urinary tract } \\
\text { infection }\end{array}$ & $1(1 \%)$ & $1(0.5 \%)$ & 3.02 & $0.19 ; 48.7$ & 0.5 \\
\hline Anemia & $9(9 \%)$ & $32(16 \%)$ & 0.52 & $0.24 ; 1.14$ & 0.32 \\
\hline \multicolumn{6}{|c|}{ Obstetric complications } \\
\hline $\begin{array}{c}\text { Retro-placental } \\
\text { hematoma }\end{array}$ & $2(2 \%)$ & 0 & 0 & 0 & 1 \\
\hline Eclampsia & $3(3 \%)$ & $11(5.5 \%)$ & 0.53 & $0.14 ; 1.94$ & 0.31 \\
\hline Preterm delivery & $6(6 \%)$ & $21(10.5 \%)$ & 0.54 & $0.21 ; 1.38$ & 0.3 \\
\hline Jo complications & $50(50 \%)$ & $103(51.5 \%)$ & 0.94 & $0.58 ; 1.52$ & 0.03 \\
\hline
\end{tabular}

Table 3. Newborns characteristics

\begin{tabular}{|c|c|c|c|}
\hline Parameter & Case n (\%) & Control n (\%) & $P$ \\
\hline \multicolumn{4}{|c|}{ Gestational Age } \\
\hline Normal term $(37-42 w)$ & $83(83 \%)$ & $168(84 \%)$ & 0.04 \\
\hline Post term $(>42 w)$ & 0 & $8(4 \%)$ & 0.31 \\
\hline Premature (33w-36w +6 days) & $13(13 \%)$ & $20(10 \%)$ & 0.15 \\
\hline $\begin{array}{c}\text { Medium premature }(28 w \text { to } 32 w+ \\
6 \text { days })\end{array}$ & $4(4 \%)$ & $2(1 \%)$ & 0.61 \\
\hline Very premature $(<28 w)$ & 0 & $2(1 \%)$ & 1 \\
\hline \multicolumn{4}{|c|}{ Birth weight } \\
\hline$<2500 \mathrm{~g}$ & $27(27 \%)$ & $56(28 \%)$ & 0.89 \\
\hline $2500-4000 \mathrm{~g}$ & $64(64 \%)$ & $138(68 \%)$ & 0.09 \\
\hline$>4000 \mathrm{~g}$ & $9(9 \%)$ & $8(4 \%)$ & 0.13 \\
\hline \multicolumn{4}{|c|}{ APGAR score } \\
\hline APGAR score $<7$ at $5 \mathrm{~min}$ & $35(35 \%)$ & $53(26.5 \%)$ & 0.02 \\
\hline APGAR score $>7$ at $5 \mathrm{~min}$ & $65(65 \%)$ & $147(73.5 \%)$ & 0.2 \\
\hline
\end{tabular}


Table 4. Neonatal prognosis

\begin{tabular}{c|ccccc} 
Outcome & Cases n(\%) & Controln(\%) & OR & CI (95\%) & $P$ \\
\hline Delivery in term & $83(83 \%)$ & $168(84 \%)$ & 0.94 & $0.53 ; 1.66$ & 0.94 \\
Preterm & $17(17 \%)$ & $24(12 \%)$ & 1.5 & $0.76 ; 2.94$ & 0.31 \\
$\begin{array}{c}\text { Post-term } \\
\text { Low birth weight }\end{array}$ & 0 & $8(4 \%)$ & 0.24 & $0.02 ; 1.96$ & 0.28 \\
$\begin{array}{c}\text { Macrosomia } \\
\text { Congenital }\end{array}$ & $9(27 \%)$ & $57(28.5 \%)$ & 0.92 & $0.54 ; 1.58$ & 0.89 \\
malformation & $6(6 \%)$ & $8(4 \%)$ & 2.37 & $0.88 ; 6.35$ & 0.13 \\
Death & $20(20 \%)$ & $16(8 \%)$ & 2.87 & $1.41 ; 5.83$ & 0.002
\end{tabular}

Statistical analysis did not find a significant relationship between maternal age and prematurity. The proportion of preterm delivery was the same in both cases and controls $(\mathrm{OR}=0.24,95 \% \mathrm{CI}$ : 0.02 and $1.96, \mathrm{P}=0.13)$. Similarly, there was no statistically significant association between the age of the mother and post term delivery. Statistical analysis found no significant relationship between maternal age and low birth weight $(\mathrm{OR}=2.37,95 \% \mathrm{CI}$ : 0.88 and $6.35, \mathrm{P}=0.07)$. Nevertheless, the risk of having a low Apgar score at birth was higher $(\mathrm{OR}=0.53,95 \% \mathrm{CI}: 0.32$ and $0.88, \mathrm{P}=0.02)$. At $5 \%$, we found no statistically significant association between maternal age and congenital malformations ( $\mathrm{OR}=3.12,95 \% \mathrm{CI}$ : 0.86 and $11.34, \mathrm{P}=0.07$ ). Statistical analysis showed that cases were 2.87 times more likely to have a deceased child than controls $(\mathrm{OR}=2.87,95 \% \mathrm{CI}$ : 1.41 and $5.83, \mathrm{P}=0.002)$.

\section{Discussion}

The impact of advanced maternal age on pregnancy outcomes remains controversial, with sometimes contradictory results in the literature. Perinatal outcomes are a source of ongoing debate, with some studies describing comparable results in different age groups (Bianco et al., 1996) and others reporting an increase in perinatal risk (Delbaere et al., 2007; Berkowitz et al., 1990). The mean parity of the cases was 6.83 children and that of the controls was 2.33 children. The maximum parity was 14 for the cases and 10 for the controls. For cultural reasons and low adherence to family planning and contraception methods, women marry very early in our countries and continue to give birth until an advanced age. This, however, results to a high rate of grand multiparas and high average parity, which is of 7 children per woman in Niger. The aims of antenatal care are to prevent, detect early, and manage complications that may affect the health of the mother and the unborn child, and also to co-operate with the woman and her family during pregnancy 
(Ngassam et al., 2013). Regular monitoring of pregnancies deemed at risk is an absolute necessity in order to diagnose problems and solve them at an early stage (Khoshnood et al., 2008). Repetitive pregnancies can negatively affect the health of the mother and the uterus. Some authors report that the negative perinatal prognosis of elderly women's pregnancies is due to several morbidity factors such as poor intra-uterine environment and deficient placentation due to vascular alteration of the elderly woman (Crawford et al., 1997). Several case-control studies (Lisonkoya et al., 2013; Xiaoli et al., 2014; Khalil et al., 2013) reported a predominance of low birth weight and macrosomia from elderly women contrary to our study where cases and controls had the same risk. In series reported by Timofeev et al. and Carolan et al. (2013), premature delivery is more common in women under 20 and over 35 years of age. Advanced maternal age is not significantly associated with preterm delivery in our study. Newborns from elderly mothers are more likely to have a low Apgar score at the first 5 minutes. Several similar results have been reported in the literature (Lamminpaa et al., 2012; Ngassam et al., 2013). Congenital malformations are higher in elderly women than in younger women, although we did not find a statistically significant relationship between advanced age and congenital malformations. However, for Roman et al. (2004), the risk for the occurrence of chromosomal abnormalities is multiplied by 7 in elderly women. The results of Vincent et al. (2012) corroborate those of Roman with $6.3 \%$ of newborns having malformation in the cases as opposed to $0.84 \%$ in the controls. Neonatal mortality was 2.87 times higher in elderly women than in controls. The main causes of death were asphyxia, neonatal infections, and birth defects. Several authors (Jahromi et al., 2008; Koo et al., 2012; and Roman et al., 2004) reported a higher risk of neonatal mortality in older women. Our study has several limitations. First of all is the sample size and duration of the study, which did not allow us to draw exhaustive conclusions. The second difficulty is the determination of gestational age which is approximate in some women. The third difficulty is the very short follow-up time for apparently healthy newborns that are released after only 6 hours of surveillance. Finally, we did not meet all the requirements from a comparability point of view. Not-with-standing, this work may allow us to contribute to the knowledge of the relationships between maternal age and perinatal risk.

\section{Conclusion}

Birth from women of advanced age is a general phenomenon in the world. Several studies have shown that advanced maternal age is an obstetrical and neonatal risk factor. In our study, neonatal mortality among women over 35 years of age was 2.87 times higher than among women aged 20 to 34 years. However, the advanced age of parturient women did not prove to be a risk 
factor for caesarean delivery, low birth weight, prematurity, macrosomia or congenital malformation. Further studies are needed to confirm or refute our findings.

\section{References:}

1. Berkowitz, GS., Skovron, ML., Lapinski, RH. \& Berkowitz, RL. (1990). Delayed childbearing and the outcome of pregnancy. N Engl J Med; 322: 659-664.

2. Bianco, A., Stone, J., Lynch, L., Lapinski, R., Berkowitz, G. \& Berkowitz, RL. (1996). Pregnancy outcome at age 40 and older. ObstetGynecol; 87:917-22.

3. Carolan, MC. Davey, MA. Biro, M. \& Kealy, M. (2013). Very advanced maternal age and morbidity in Victoria, Australia: a population based study. BMC Pregnancy and Childbirth2013; 13:8086.

4. Cleary-Goldman, J., Malone, FD. Vidaver, J., Ball, RH., Nyberg, DA., \& Comstock, $\mathrm{CH}$ et al. (2005). Impact of maternal age on obstetric outcome. ObstetGynecol; 105:983-90.

5. Crawford, BS., Davis, J. \& Harrigill, K. (1997). Uterine artery atherosclerotic disease: histologic features and clinical correlation. ObstetGynecol; 90:210-215.

6. Delbaere, I., Verstraelen, H., Goetgeluk, S., Martens, G., De Backer, G. \& Temmerman, M. (2007). Pregnancy outcome in primiparae of advanced maternal age. Eur J ObstetGynecolReprodBiol; 135:41-6.

7. Jahromi, BN. \& Husseini, Z. (2008). Pregnancy outcome at maternal age 40 and older. Taiwan J ObstetGynecol; 47(3):318-321.

8. Joseph, KS., Allen, AC., Dodds, L., Turner, LA., Scott, H. \& Liston, R. (2005). The perinatal effects of delayed childbearing. ObstetGynecol; 105: 1410-1418.

9. Khalil, A., Syngelaki, A., Maiz, N., Zinevich, Y. \& Nicolaides, KH. (2013). Maternal age and adverse pregnancy outcome: a cohort study. Ultrasound ObstetGynecol; 42: 634-643.

10. Khoshnood, B., Bouvier-Colle, MH., Leridon, H. \& Blondel, B. (2008). Impact of high maternal age on fertility, maternal health and child health. J jgyn; 217(3):217-13.

11. Koo, Y-J., Ryu, H-M., Yang, J-H., Lim, J-H., Lee, J-E., Kim, M-Y et al. (2012). Pregnancy outcomes according to increasing maternal age. Taiwan J ObstetGynecol; 51: 60-65.

12. Lamminpää, R., Vehviläinen-Julkunen, K., Gissler, M. \& Heinonen, S. (2012). Preeclampsia complicated by advanced maternal age: a registry-based study on primiparous women in Finland 1997-2008. BMC Pregnancy and Childbirth; 12:47-51 
13. Lisonkova, S., Paré, E. \& Joseph, KS. (2013). Does advanced maternal age confer a survival advantage to infants born at early gestation? BMC Pregnancy and Childbirth;. 13:87-95

14. Ngassam, AN., Dohbit, JS., Nzedjom, C. \& Kasia, JM. (2013). Pregnancy outcome at advanced maternal age in a group of African women in two teaching Hospitals in Yaounde, Cameroon. Pan Afri Med J 2013; 14: 134.

15. Roman, H., Robillard, PY., Julien, C., Kauffmann, E., Laffitte, A., Gabriele, $M$ et al. (2004). Pregnancy in 382 women over 40 years: a retrospective study in the population of the island of Reunion. J Gyn; 11:33-7.

16. Statistics Canada (2009). Births. Ottawa: Minister of Industry; 2012. http://www.statcan.gc.ca/pub/84f0210x/84f0210x2009000- eng.pdf. Accessed in May 2017.

17. Statistics Canada, Canadian Vital Statistics, Birth and Stillbirth Data bases 3231 and 3234. CANSIM Tables number 102-4515: Live births and fetal deaths (stillbirths), by type (single or multiple), Canada, provinces and territories, annual (number). http://estat.statcan.gc.ca/cgi-win/cnsmcgi.pgm

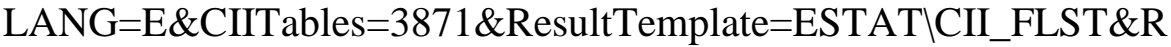
OOTDIR $=E S T A T / \&$ LangFldr $=E n g l i s h / \& C 2 D B=$. Table number 102-4515. Accessed in May 2017.

18. Timofeev, J., Reddy, UM., Huang, CC., Driggers, RW., Landy, HJ. \& Laughon, SK. (2013). Obstetric Complications, Neonatal Morbidity, and Indications for Cesarean Delivery by Maternal Age. Obstet Gynecol ; 122(6): 1184-1195.

19. Vincent-Rohfritsch, A., Le Ray, C., Anselem, O., Cabrol, D. \& Goffinet, F. (2012). Pregnancies at 43 years old and over: maternal and perinatal risks. J Gyn; 04.013.

20. Xiaoli, L. \& Weiyuan, Z. (2014). Effect of maternal age on pregnancy: a retrospective cohort study. Chin Med J; 127 (12): 2241-2246. 